\title{
Trends in Analytical Chemistry 67(2015)45-55
}

\section{An introduction to dengue-disease diagnostics}

\author{
Nadiya Taha Darwish, Yatimah Binti Alias, Sook Mei Khor * \\ Department of Chemistry, Faculty of Science, University of Malaya, Kuala Lumpur 50603, Malaysia
}

\section{A R T I C L E I N F O}

\section{Keywords:}

Biomarker

Biosensor

Capture IgM

Dengue NS1 antigen

Dengue virus

Diagnosis

IgG ELISA

Immunochromatography

Real-time polymerase chain reaction

Virus isolation

\begin{abstract}
A B S T R A C T
In this review, we discuss how dengue disease can be diagnosed accurately at the viremia phase and the fever phase. Diagnostic tools currently used to detect dengue virus (DENV) are virus isolation, capture IgM and IgG ELISA, real-time polymerase chain reaction (RT-PCR), and immunochromatography of the dengue NS1 antigen. First, we explain the advantages, the challenges and the limitations of different diagnostic tests. This account is followed by several examples using biosensors for detection of several important DENV biomarkers. Finally, we discuss our opinions regarding future perspectives in this field.
\end{abstract}

Contents

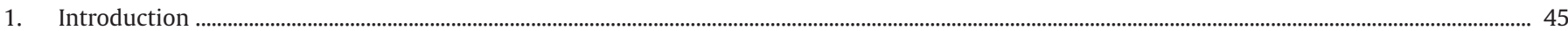

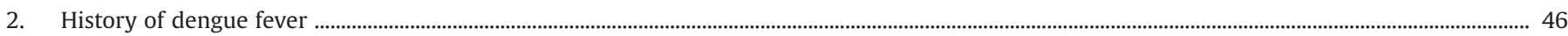

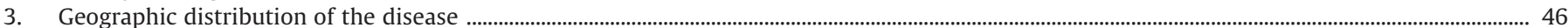

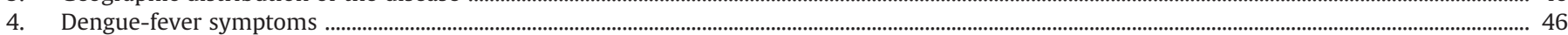

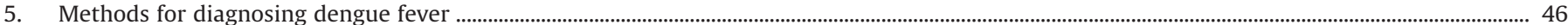

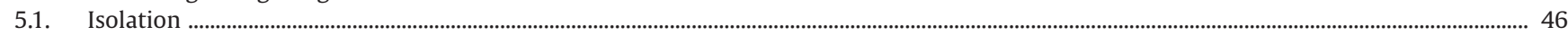

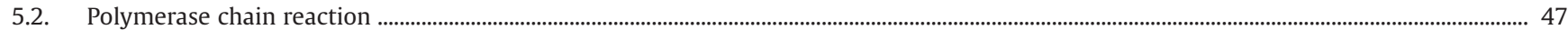

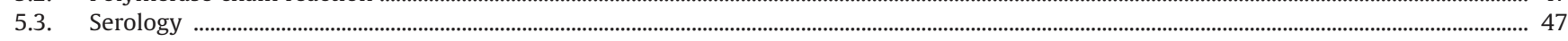

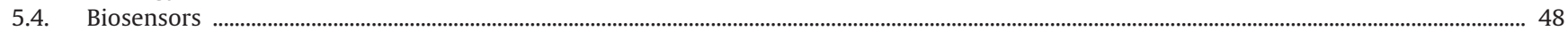

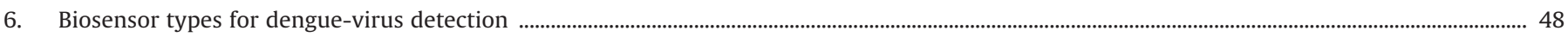

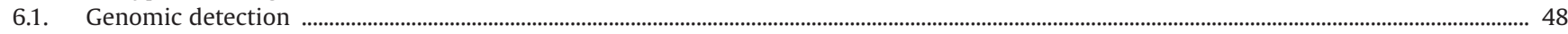

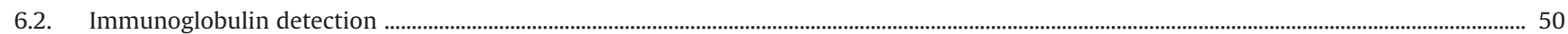

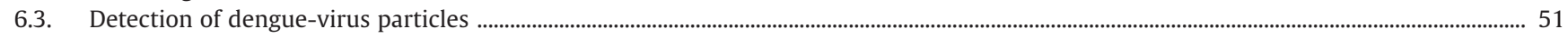

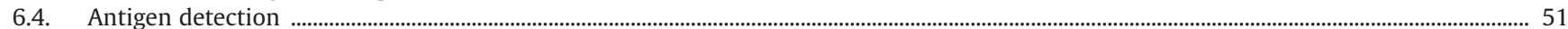

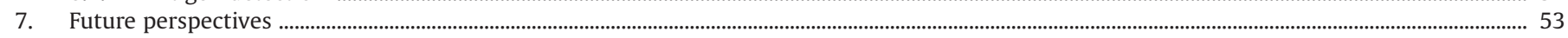

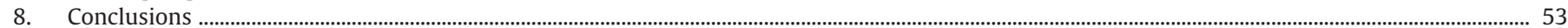

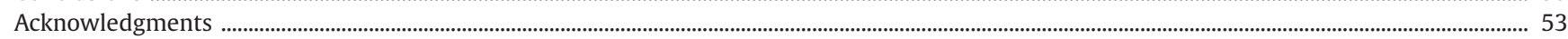

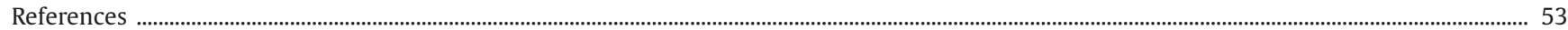

\section{Introduction}

Dengue viruses (DENV) are arboviruses (arthropod-borne viruses) and classified under the Flavivirus genus, which also contains the West Nile virus, yellow fever virus, and encephalitis virus. The dengue virus is enveloped, is spherical with a diameter of $50 \mathrm{~nm}$ and consists of a single, positive-sense RNA genome of about 11,000 nucleotides with only one open-reading frame. This open-reading

\footnotetext{
* Corresponding author. Tel: +603 79677022, Ext. 2520; Fax: +603 79674193.

E-mail address: naomikhor@um.edu.my (S.M. Khor).
}

frame encodes a single polyprotein precursor arranged in an $\mathrm{NH}_{2}-$ C-prM-E-NS1-NS2A-NS2B-NS3-NS4A-NS4B-NS5-COOH sequence. Co-translational and post-translational proteolytic processing gives rise to three structural proteins that form the virion: the $\mathrm{C}$ protein encapsulates the viral genomic RNA to form the nucleocapsid, and the nucleocapsid is enveloped by a lipid bilayer in which viral membrane (prM protein) and envelope protein (E protein) are embedded $[1,2]$. Dengue non-structural proteins (NS1-NS5), which are expressed in infected cells, are essential for virus replication, virion assembly, and avoiding the host immune response. Primarily, the non-structural proteins exist in the cytoplasm to form replication products that subsequently help in viral RNA synthesis. However, 
DENV NS1, a hydrophilic membrane-associated homodimer, is synthesized in the endoplasmic reticulum. The C-terminal residues of NS1 are probably involved in NS1-associated pathogenesis, as the mutation in NS1 protein is known to disrupt RNA synthesis, so exploration of the three-dimensional structures of the NS1 protein and the viral NS1-NS2A catalytic domain will contribute to understanding of the conformation of NS1 subunit, and its implication in viral pathogenesis. NS2B works as chaperone that participates in the folding of the NS3 subunit in its active conformation, and is implicated in regulating substrate-enzyme interaction and in membrane association. The best characterized DENV non-structural proteins are NS3 and NS5, which are multifunctional proteins involved in enzymatic activities. NS4 consists of two subunits, NS4A and NS4B; NS4A is involved in intracellular membrane modulation and its C-terminal end helps in the translocation of NS4B subunit. However, the function of the NS4B subunit is not understood, although recent studies suggest that it acts as an interferon antagonist $[2,3]$.

DENV is an RNA Flavivirus that has four serotypes, numbered DENV1, DENV2, DENV3 and DENV4 and categorized by the number of antigens that the viruses have in common. Dengue was earlier classified via the World Health Organization categorization into dengue fever (DF), dengue hemorrhagic fever (DHF) and dengue shock syndrome (DSS). Case evaluation has not always identified an infected person when they are in danger of harsh sickness, and the classification is simply as having ungenerous or severe infection. A patient who is infected with one serologic type does not acquire immunity to dengue's other serotypes. The primary infection of DF could convert to harsh sickness in the next infection with other serotypes. Immunity after infection is type-specific, and immunity for all serotypes is maintained for a short time [4].

Nevertheless, the viruses are cross-reactive, there is no crossprotective immunity; a person could be infected with DF up to four times, given the opportunity for different serotypes of the illness, ranging from DF to DHF and DSS [5,6]. DF transmits from one person to another by bites from the Aedes mosquito, which receives the virus from an infected person. The virus replicates inside the mosquito and is transmitted to another person whom the mosquito bites. This type of mosquito is prevalent in urban areas because the Aedes aegypti mosquito lays its eggs in water containers rather than in ponds or ditches. During the epidemic in USA in 2001, it was discovered that the Ae. albopictus, Ae. polynesiensis, and Ae. Scutellar mosquitoes can also transmit DF, while only Ae. albopictus was found during the Hawaiian outbreak $[5,7,8]$.

\section{History of dengue fever}

The first report for a sickness similar to DF was in the late eighteenth century, and it was a temporary outbreak. It is assumed that DF was initially transmitted by travel and trade shipping between Asia and South America. The DF pandemic that occurred following World War II was due to environmental damage, displaced people, and discarded military equipment, which became hosts for vector reproduction. In the twentieth century, DHF/DSS was identified as a diagnostic sign for dengue infection. Afterwards, cases have increased internationally, and dengue disease has been transmitted to other areas of the world [8].

Deadly dengue infection was first documented in an outbreak in Manila, Philippines, in 1953-54. For 10-15 years, it developed to being endemic throughout Southeast Asia. The first epidemic in Singapore was in 1960 and infected older children and adults, with a low mortality rate. In 1996, a harsh outbreak of dengue/DHF occurred in Delhi, and approximately 10,252 cases were reported; there were 423 deaths [7].

Associated work started in 1949 to minimize mosquito reproduction, which subsequently decreased the number of DF cases. Nevertheless, reduction in the use of the anti-insect dichlorodiphenyltrichloroethane (more commonly known as DDT) caused a rise in DF cases in 1970, and it was one of the most pandemic diseases [5].

Although the WHO data between 1992 and 1998 show that Southeast Asia has had a stable number of DF cases, the rate of cases in the Western Pacific has increased four-fold. The numbers in the Americas increased eight-fold during the same period. WHO in 1980 stated that $1,033,417$ is the number of DF in the American region. By 2002, that number had climbed to $8,491,416$. At present, approximately 100 countries have endemic DF, with 100 million cases predicted yearly [5].

\section{Geographic distribution of the disease}

The regions with the maximum disease infections are in the AsiaPacific region, both central and south America and southeast of the Gulf of Mexico. Dengue is found in Africa but is less frequent there. In 2009, dengue re-emerged in Florida after a 75-year absence. In 2010, epidemics have been declared in the Philippines, the Caribbean, Central America and Sri Lanka. It is expected that, in 2020, the number of travelers could rise with international arrivals reaching some 1.6 billion, especially in common tourist destinations [4].

DF reproduces in subtropical and tropical regions because climate affects the reproduction and the incubation stage of the DENV in the Aedes mosquito, and the harshness of the epidemic. A congested urban region with inappropriate hygiene can affect outbreaks of DF [5]. Global warming and climate change could help the spread, the prevalence, and the geographic range of DF. Warming global temperatures boost the risk of contact with infections by increasing the rainfall and the habitat for vectors [5].

\section{Dengue-fever symptoms}

DF presents with different symptoms, from basically no symptoms to severe disease. A second infection with another serotype of the virus can cause an endothelial leak and bleeding, which are symptoms of DHF. A small number of patients with DHF can develop circulatory failure and refractory shock, known as DSS, which could be fatal. However, DHF and DSS based on the disease serotype perhaps occur with a first dengue attack [7]. The mortality rate for (DSS) dengue is quoted as being 1-5\% [4]. The incubation period of DF after the mosquito bite is usually 4-7 days, and the range 3-14 days. Typically, the disease appears with a high fever that could reach $39^{\circ} \mathrm{C}$ or higher [7].

Usually, there are also spots, nausea and vomiting, and harsh muscular pains and headache could be present $[4,6]$. DHF is known mainly through the hemoglobin concentration, hemorrhagic symptoms and vascular leakage, and could subsequently end the patient's life. The disease development to DHF is inadequately known; however, it could develop because of the viral virulence antigen, host hereditary and acquired factors, multiple infections and immune pathological reactions [9].

\section{Methods for diagnosing dengue fever}

There are several types of tests for detecting the DENV. The traditional diagnostic techniques for the DENV is its isolation in cell culture, serological testing, PCR and, more recently, biosensors and fast methods.

\subsection{Isolation}

The conventional test to identify DENV is virus isolation in a cell culture or live mosquitoes, which was the preferred test in the last century $[10,11]$. Isolated viruses can be used for virological analyses, which could also give molecular epidemiological information by analyzing isolated viruses. Thus, virus isolation can provide 
additional data about the patients. Although virus isolation is suggested as the best diagnostic test in some published research, it is done by using dengue type-specific monoclonal antibodies for immuno-fluorescent staining, and the results show that virus isolation can be integrated as part of the detection process [12]. The isolation technique has been shown to be more effective than the PCR; however, this degree of efficiency can be approached only if the sera samples are collected before fever onset [11,13].

Although the specificity is $100 \%$ for real-time PCR (RT-PCR) and virus isolation, the specificity of the cell-culture sensitivity technique was shown to be only $63 \%$ [14]. Virus isolation requires expensive laboratory equipment and chemicals to preserve the cell line and requires days to weeks; successful isolation is frequently less than the mean for several reasons, such as low numbers of viable virus, unsuitable preparation of samples, and construction of virusantibody complexes [15]. Diagnosis by virus isolation is in the range $20-80 \%$, because only the active virus can reproduce in the cell culture, and this aspect greatly depends on specimen collection $[14,16]$.

\subsection{Polymerase chain reaction}

Polymerase chain reaction (PCR) is amplification of DNA to produce cDNA from a target RNA through a reverse-transcriptionreaction technique; PCR has been used globally for robust, sensitive detection of DENV and other infectious diseases. Many of the (RT$\mathrm{PCR}$ ) protocols have been claimed to diagnose and to identify dengue serotypes in clinical samples [17-27].

The samples, as reported, were collected from different sources, such as sera [28], plasma [29], tissue from fatal cases [30], mosquitos [31], infected cell cultures [32], central nervous system (CNS) [33], saliva and urine [34], and blood dropped onto filter paper [35]. Those procedures vary in RNA-purification procedures, primer sites, methods to detect the RT-PCR products, and methods of virus typing. The most important factor for the success of the PCR protocol is to utilize the most conserved coding region, but it is difficult to identify the true conserved coding region because of the instability of the viral genome. Many regions in the dengue genome have been proposed for the PCR technique, such as the capsid region (C), envelope protein (E), prM region and non-structural proteins NS1, NS2A, NS2B, NS, and NS5 $[15,36]$. The DENV 3'-noncoding region ( $3^{\prime}-$ NR), which has almost $400 \mathrm{bp}$, is proposed as the most conserved sequence for serotypes and serotype-specific detection sequences [37]. Other factors that also have a strong impact on the PCR sensitivity are the quantity of RNA used for the RT step [28], the PCR parameters and the performance of the enzymes [15]. Gamma irradiation could also have a considerable influence on the sensitivity of the PCR. By using long amplification products, the diagnostic protocol might be less sensitive than procedures based on short amplicons. The effect of gamma irradiation was obvious when a 2050-bp RNA sequence in a Nested RT-PCR was used while no remarkable damage was observed to the specimen of $<600$ bp that was treated by a gamma irradiation and tested by RT-PCR [38].

Moreover, some of the RT-PCR protocols contain PCR inhibitors, such as antibiotics and hemoglobin, which might explain some of the loss of sensitivity due to their direct conjugation with DNA or DNA polymerases $[35,39]$. Thermal cycler type can also interfere with amplification [40]. Although false-positive results and cross reactivity can be overcome by excluding sequences that are mutual in both the DENV genome and the DNA/RNA of the human, mosquito and contaminants during the primer designs [41], most of the RT-PCR protocols suffer from two problems:

- a false-negative result because of the variation in the DENV serotypes; and,

- the absence of a standard protocol.
Furthermore, PCR can detect an infection during only the early phase of the infection, and it is not efficient after 5-7 days; using RT-PCR for dengue detection is not convenient in an endemic region, because it requires costly reagents and apparatuses, and specific training.

\subsection{Serology}

Serology usually refers to the diagnostic identification of antibodies in the serum and other body fluids. IgM, IgG and, more recently, NS1 are mostly used in serological detection. For a primary dengue infection, the acquired immune response is typically identified by a slow, low-titer increase in the IgM antibody starting by days $3-5$, and the IgG is quantifiable by days $5-7$ of the illness. Unfortunately, through a subsequent infection, IgM titers rise much more slowly than IgG titers and could result in false-negative results. However, IgG levels rise rapidly in the second infection and might be found during the acute stage of the disease. IgG levels could persevere for years and show high reactivity with other flaviviruses [36].

Conventionally, the hemagglutination-inhibition (HAI) assay has been utilized to discriminate between primary and secondary dengue infection [42]. However, HAI lacks serotyping specificity and is unobtainable as a commercial test kit [10]. MAC-ELISA-IgM is utilized to detect dengue-specific IgM antibodies in the patient's sera via immobilized IgM, where the anti-human IgM antibody is first fixed on the ELISA wells [43]. False-positive readings in this test have mainly been ascribed to cross-reactivity with co-circulating antibodies from other flaviviruses, such as in the serum of patients with malaria or leptospirosis [36] and patients with Japanese encephalitis [44].

MAC-ELISA Anti-dengue IgG detection is also conducted by fixed IgG via anti-human IgG antibody that was immobilized earlier on the plate wells. However, dengue-specific IgG tests are less specific than IgM because IgG is cross-reactive and has no conserved epitopes among the four serotypes, unlike IgM, which interacts only with epitopes of the infecting serotype present [45]. The performance and the specificity of classical serological techniques for dengue diagnosis depend on many factors, such as the quality of the antigens that are utilized with the ELISA method, the specimen type (e.g., serum, whole blood or saliva), the DENV serotype [10] and the IgM and IgG titers [28].

An immunochromatography test (e.g., dengue NS1 Ag STRIP Kit) is used for DENV detection. The strip used in this point-of-care study consists of two lines:

- a control line ('biotin-gold colloidal particles coated with streptavidin' complex); and,

- a test line ['monoclonal anti-NS1 antibodies (mAb)-NS1 Aggold colloidal particles coated with anti-NS1 mAb' complex].

The appearance of both test and control lines after incubating in a serum sample with an assay time of $15 \mathrm{~min}$ indicates a positive result. Although this test is simple enough to be performed in any laboratory and it offers an excellent specificity, the detection sensitivity depends solely on the DENV serotype and number of infections $[46,47]$. In other words, the dengue NS1 Ag STRIP Kit is less sensitive and less accurate than a PCR test [46].

In conclusion, serological tests using IgM and IgG are potentially cross-reacting with co-circulating flavivirus antibodies as a result of prior infection or vaccination (e.g., Japanese encephalitis virus, or Powassan/Deer tick virus). Moreover, these tests require two sera specimens (taken in the acute and convalescence phases) [48]. Because of these limitations, more than one test (e.g., NS1 antigen ELISA, IgM antibody ELISA and/or rRT-PCR) are proposed to ensure that the disease is in the patient's serum $[48,49]$. The NS1 antigen test should be used as a complementary test, as the sensitivity and 
Table 1

Classification of biosensors for dengue virus detection

\begin{tabular}{|c|c|c|c|c|c|}
\hline Biosensor type & Advantages & Disadvantages & Limitation & Challenges & Ref. \\
\hline Piezoelectric & $\begin{array}{l}\text { Sensitive due to the high elastic } \\
\text { modulus, cost effective for imprinted } \\
\text { polymers as no monoclonal antibodies } \\
\text { used }\end{array}$ & $\begin{array}{l}\text { Inadequate recognition properties in } \\
\text { imprinted polymers }\end{array}$ & $\begin{array}{l}\text { High detection } \\
\text { limit of analyte }\end{array}$ & $\begin{array}{l}\text { Increase the oscillation } \\
\text { level }\end{array}$ & [52-55] \\
\hline Optical & $\begin{array}{l}\text { Potential in low detection limits and } \\
\text { useful for screening a large number of } \\
\text { samples concurrently }\end{array}$ & $\begin{array}{l}\text { Need costly microscope equipped with } \\
\text { fluorescence filters, other electronics } \\
\text { and a computer to calculate and } \\
\text { quantify the fluorescent signal }\end{array}$ & $\begin{array}{l}\text { Long time required } \\
\text { for labelling an } \\
\text { analyte }\end{array}$ & Label free detection & [56-63] \\
\hline Electrochemical & $\begin{array}{l}\text { High sensitivity, simplicity, and low } \\
\text { cost }\end{array}$ & $\begin{array}{l}\text { Labelling target analyte requires more } \\
\text { time }\end{array}$ & $\begin{array}{l}\text { Limited size of the } \\
\text { electroactive area }\end{array}$ & $\begin{array}{l}\text { Boosting the interface of } \\
\text { biorecognition element } \\
\text { with the electrode surface }\end{array}$ & [64-70] \\
\hline
\end{tabular}

the specificity of dengue disease diagnostics can be enhanced when the NS1 antigen test is performed together with the IgM capture ELISA $[47,50]$.

\subsection{Biosensors}

Different analyte probes were used for DF detection, such as RNA, cDNA, IgM, IgG, Glycoprotein-E, NS1 protein and viral particles, so various types of biosensor have been applied to detect these analytes.

First, piezoelectric sensors work using an oscillating voltage at the resonance frequency of the piezoelectric crystal and detecting the frequency alterations according to the required analyte binding with biomolecules on the crystal face. Often used, piezoelectric sensors are classified into quartz-crystal microbalance (QCM), surface acoustic wave (SAW) and bulk acoustic wave (BAW).

Second, an optical biosensor is based on converting a natural response by an optical signal, such as the absorbance, fluorescence, chemiluminescence, of surface-plasmon resonance, to monitor the alteration in reflected light [51].

Third, electrochemical biosensors are based on stimulating the analyte by labeling or tagging an important element in an electrochemical reaction (Table 1 ). Frequently applied labels might be enzymes (e.g., peroxidase, glucose oxidase, alkaline phosphatase or catalase), ferrocene or $\operatorname{In}^{2+}$ salts, and redox mediators (e.g., $\mathrm{K}_{3} \mathrm{Fe}[(\mathrm{CN})]_{6}{ }^{3-14-}$ or methylene blue).

Electrochemical sensors can be classified into different types according to their measurement modes $\{$ e.g., potentiometric (voltage), amperometric (current), impedimetric (impedance), conductimetric (conductance) and field-effect transistors (voltage) [51]\}.

\section{Biosensor types for dengue-virus detection}

\subsection{Genomic detection}

Table 2 shows the classification of DENV analytes. Based on studies performed by Baeumner et al. $[80,81]$, the nucleic-acid sequence-based amplification (NASBA) technique has been further improved [56] by using electrochemiluminescence and liposome amplification. The reporter (DNA probe) is connected to the exterior of dye-covered liposomes. The capture probes (dengue serotypespecific probes) are placed on a strip of polyether-sulfone membrane. An amplified target sequence is added to the liposomes and is then introduced to the membrane. After migration of the mixture, the liposome-target sequence couples are placed in the capture zone by hybridization of the target sequence with a capture probe. The quantity of the target sequence is represented by the liposome amount, which can be measured with a reflectometer device. Serotypes 1, 2 and 4 were characterized; however, serotype 3 showed little interaction with the fabricated biosensors for the detection of serotypes 1 and 4 . Nevertheless, using nucleic acid requires professional technical skills [82], and it was stated in a comparative study between (NASBA) and RT-PCR for virus diagnosis that the NASBA assay provided less reliable signals [83].

Table 2

Classification of dengue-virus analytes

\begin{tabular}{|c|c|c|c|c|c|}
\hline Detection Mode & Advantages & Disadvantages & Challenges & Limitation & Ref. \\
\hline Genomic & $\begin{array}{l}\text { Able to } \\
\text { discriminate } \\
\text { between dengue } \\
\text { virus serotypes }\end{array}$ & $\begin{array}{l}\text { Required high technical } \\
\text { skill for nucleic acid } \\
\text { isolation }\end{array}$ & $\begin{array}{l}\text { Instability of viral nucleic } \\
\text { acid }\end{array}$ & Detection within viremia phase only & {$[52,56-58,71-76]$} \\
\hline Immunoglobulin & $\begin{array}{l}\text { Easy sample } \\
\text { preparation from } \\
\text { patient sera }\end{array}$ & $\begin{array}{l}\text { Required pair of specimens } \\
\text { (from viremia and } \\
\text { convalescence phases). } \\
\text { Cross-reactivity with co- } \\
\text { circulating flavivirus } \\
\text { antibodies }\end{array}$ & $\begin{array}{l}\text { Prolonged time for primary } \\
\text { and secondary antibodies' } \\
\text { incubation and blocking } \\
\text { steps }\end{array}$ & $\begin{array}{l}\text { Primary dengue infection is characterized by a } \\
\text { slow and low titer of IgG antibody response. } \\
\text { IgG antibodies rise rapidly in second infection }\end{array}$ & [59-61] \\
\hline Virus particle & $\begin{array}{l}\text { Only specific for } \\
\text { dengue virus } \\
\text { detection }\end{array}$ & $\begin{array}{l}\text { Detection for only specific } \\
\text { dengue serotypes }\end{array}$ & $\begin{array}{l}\text { Virus sensing by specific } \\
\text { binding of dengue viral } \\
\text { particles to its serotype } \\
\text { 2-specific immunoglobulin } \\
\text { G antibody within the thin } \\
\text { alumina layer }\end{array}$ & Detectable within viremia phase only & {$[77,78]$} \\
\hline Antigen & $\begin{array}{l}\text { Easy sample } \\
\text { preparation from } \\
\text { patient sera }\end{array}$ & $\begin{array}{l}\text { Cross-reactivity with both } \\
\text { co-circulating flavivirus } \\
\text { antibodies IgM and IgG }\end{array}$ & $\begin{array}{l}\text { To immobilize the antigen } \\
\text { on the electrode surface } \\
\text { with high intensity and } \\
\text { high activity }\end{array}$ & $\begin{array}{l}\text { Specific to one analyte such as virus } \\
\text { glycoprotein, envelope protein (E-protein) and } \\
\text { NS1.The electrode modification's compound } \\
\text { has to react with different glycoprotein pattern } \\
\text { in investigated sera }\end{array}$ & {$[53,54,64-68,79]$} \\
\hline
\end{tabular}


A microfluidic biosensor by RNA hybridization and fluorescence detection was also proposed for dengue RNA diagnosis. In this biosensor, magnetic beads were used to carry the capture probe, and the reporter probes were attached to liposomes (Fig. 1). If a dengue nucleic acid is available, then a homology occurs between the capture probe and the specific nucleic acid on one side and the reporter probe and the same RNA molecule on the other side. When the specific sandwich is formed, it will be detected by intact liposomes with encapsulated fluorescent dye via fluorescence microscopy by adding the detergent solution ( $n$-octyl B -Dglucopyranoside, OG). The RNA detection capability was $0.125 \mathrm{nM}$ and $50 \mathrm{pM}$ for intact and lysed liposomes, and it could discriminate between DENV serotypes 1-4 [57].

Electrochemical biosensors have also been used in detecting DENV nucleic acid. An electrochemical microfluidic biosensor (miniEC) replaced fluorescence detection with electrochemical detection. Liposome signal amplification for hybridized RNA in an integrated minipotentiostat device was also presented, utilizing short-sequence DNA probes that have homology with the nucleic-acid RNA or DNA. Magnetic isolation is the basis for this device by linking magnetic microbeads to a capture probe, while the reporter probe is linked to redox label-entrapping liposomes. When the nucleic acid is captured, the lyposomes produce the redox marker and subsequently cause signal amplification. The miniEC achieved a diagnostic limit 10 times lower than that of the laboratory-bench method [71].

Use of microfluidics is good, due to the small volume of sample required, which reduces the amounts of reagents that must be used. Furthermore, a microfluidic system could enhance the efficiency and reduce cross contamination by incorporating sensing parts [72]. However, microfluidic biosensors were considered to be more efficient if microfluidic protein/enzyme-based pathogen sensing or microfluidic cell-based pathogen sensing was used instead of genetic material because of the prolonged process of DNA isolation and analysis [84].

A circulating-flow QCM was applied to diagnose dengue nucleic acid in sera that contained the DENV [52]. Two types of gold nanoparticle (AuNP) were linked to a QCM by the target sequences to amplify the signal upon DNA detection. The amplified sequences worked as a link for the layer-by-layer AuNP probe hybridization in this device. DNA-QCM biosensor results showed that it is capable of detecting the virus in sera that contain 2 plaqueforming units (pfu) $\mathrm{mL}^{-1}$ with high sensitivity and specificity. Nevertheless, DNA-QCM required high technical skills in DENV cultivation and RNA extraction [82].

As a model for electrochemical genosensors to detect the DENV RNA, Teles et al. [73] used ferrocene as an electroactive indicator based on its special adhesion to single DNA strands. Complementary DNA was immobilized on the chitosan glassy-carbon electrode (GCE) surface. Voltammetric detection based on ferrocene attachment is used when hybridization occurs between the two strands.

In another genosensor, Martins et al. [74] presented pencillead graphite (PLG) as a low cost, renewable electrode. A DNA probe with a complementary sequence was electrostatically immobilized onto a PLG electrode that was fabricated with poly-L-lysine solution. Electrochemical diagnosis of hybridization between probe and target was conducted by utilizing differential pulse voltammetry (DPV) and sweeping the electrode potential between $-6 \mathrm{~V}$ and $0 \mathrm{~V}$, using methylene blue as hybridization label. The electrode that worked only with poly-L-lysine presented no current peaks, which showed that the polymer did not interfere with the result. At the same time, the electrode that worked with modified oligonucleotides demonstrated current peaks in the potential range characteristic of an oxi-reduction process between DNA guanines and methylene blue [74]. The polymer had no intervention effect
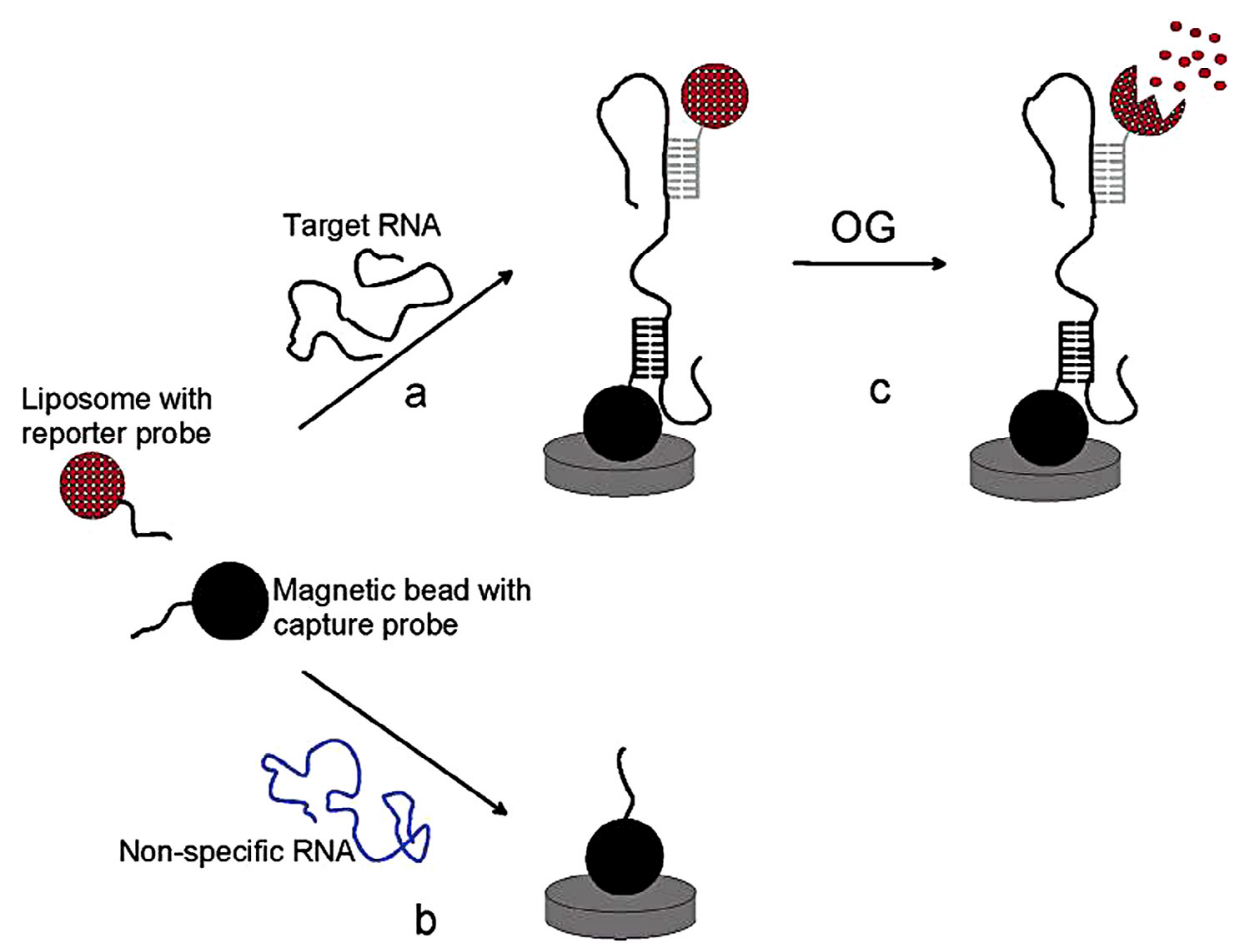

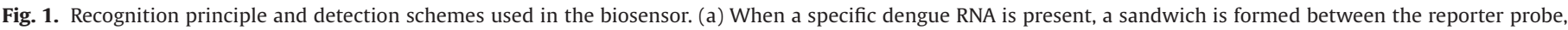

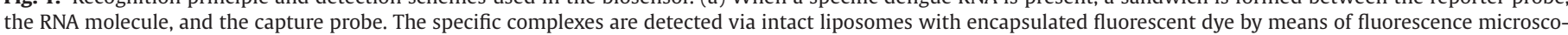

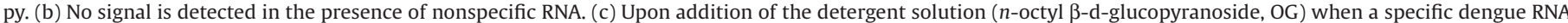

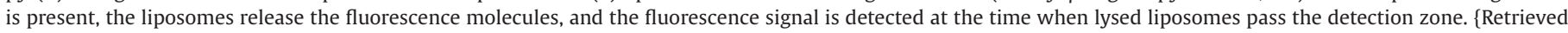
from [51]; (C2005, American Chemical Society\}. 
on the result because only the working electrode, which was modified with oligonucleotides, showed current peaks, but no signal was obtained when using a poly-l-lysine-modified electrode. However, to avoid false-negative results, a high level of optimization for the reaction condition was required to produce the detection signal by hybridization between the probe and the complementary DNA strand [75].

To identify different dengue serotypes in patients' sera at pM levels, a complex of AuNP-polyaniline hybrid and SH-terminal groups was linked to three dengue serotype-specific primers, AuNP-PANIST(1-3). The CV and EIS results showed a homology between the primers and their complementary DNA [76].

The Pan region, the mutual sequence in all four serotypes in addition to the specific sequence for each serotype, was detected by a modular fluorescent biosensor. This genomic biosensor contains linkers (target complements and triggers). When bonds form between the linker and the targeted DNA, the trigger binds to the aptamer and releases nuclease. Subsequently, the detection is performed when the nuclease cleaves a signaling molecule [58].

A label-free biosensor was designed by using a silicon nanowire (SiNW) sensor that was covalently attached to a specific peptide nucleic acid (PNA) complementary to the DEN-2 (69 bp) sequence. Electrical detection is calculated by measuring the change in the resistance before and after the hybridization. This biosensor was claimed to be able to detect DEN-2 even in the unpurified RT-PCR. Although this module is specific for only one serotype, a label-free biosensor is useful in overcoming the gradual leakage of the label, for in-the-field applications, and this approach is cost effective [85]. However, the challenge for all of these genomic biosensors is the stability of the viral genetic acids and the limitations in detecting a viral infection within only the viremia phase [53].

\subsection{Immunoglobulin detection}

There are several studies in which optical biosensors have been proposed for detecting immunoglobulins in the dengue patient's sera. Optical biosensors and fluorescence-based transducers are relatively costly, but they have potential for low limits of detection (LODs) and are useful for screening a large number of samples concurrently [71]. The chemiluminescent optical-fiber immunosensor (OFIS) was designed to detect anti-dengue (IgM) in human-serum specimens [59]. This test utilizes a colorimetric IgM capture ELISA (MAC-ELISA) (Fig. 2). Although OFIS required several steps (the addition of goat anti-human IgM, mouse anti-Den, Goat anti-mouse IgG-HRP conjugate and dengue antigen) to detect the analytes, the result showed that it is sensitive and comparable to the chemiluminescent MAC-ELISA and the colorimetric MAC-ELISA by 10 and 100 times, respectively, and chemiluminescence with OFIS could have more potential for use in the early stages of infection if recombinant protein from the envelope, the membrane or the NS1 antigen was used in this type of biosensor.

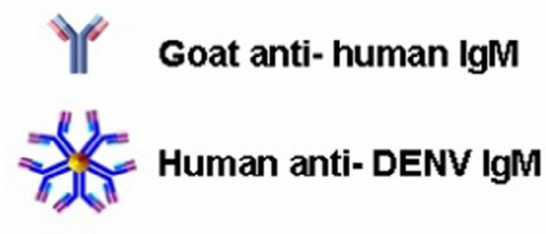

(1) Dengue antigen

Mouse anti- DENV

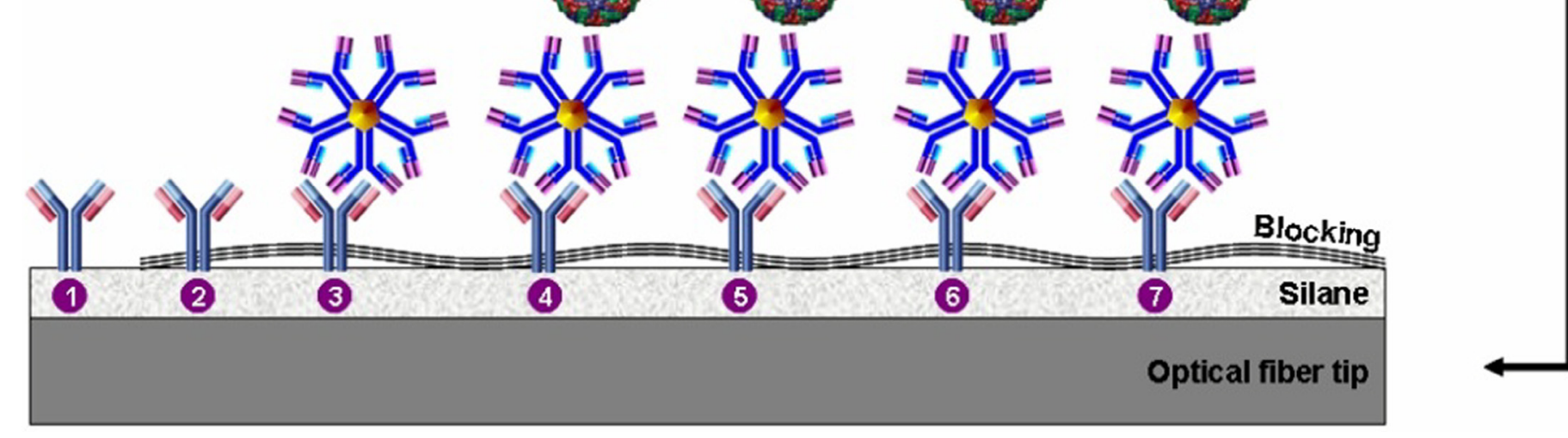

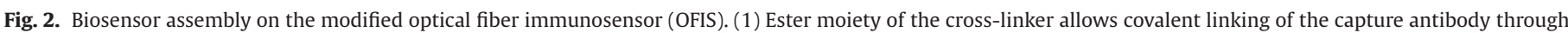

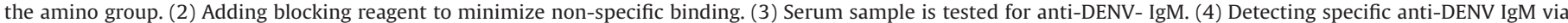

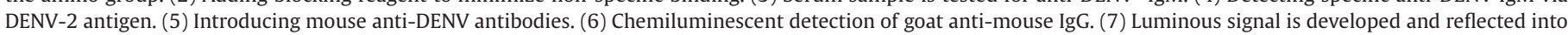
the optical fiber. \{Retrieved with permission from [74]; (C2009, Elsevier BV\}. 
Integrated fluorescent immunoassay (FIA) using a microfluidic system is an innovative biosensor. In this device, a magnetic beadvirus complex was used for fast diagnosis of the immune-globulins IgM and IgG during a dengue infection. This novel microfluidic device consisted of one-way micro-pumps, a four-membrane-type micromixer, two-way micro-pumps and an on-chip micro-coil array, to perform fast serological analysis of both IgG and IgM antibodies concurrently. The concentration of secondary antibodies with labelled fluorescence was calculated via an optical-detection module. The required time was within $30 \mathrm{~min}$, and the LOD was $21 \mathrm{pg}$ [60]. FIA is an advantageous biosensor because of its capability of detecting two analytes simultaneously, and it can show more potential if the two analytes are presented by both of the stages in a dengue infection: the viremia phase (by detecting RNA or one of the dengue antigens) and the fever phase, which starts from the fever onset onward (by detecting IgG or IgM).

Because the SPR phenomenon of label-free, real-time assay is utilized in this device to detect the DENV IgM optoelectronically, the DENV antigen (name not mentioned in this research paper) can be used as the sensing element [61]. In the SPR phenomenon, when a biomolecule is attached to a metal surface, alteration in the refractive index changes the angle of incidence, which subsequently causes SPR excitation [62]. In this biosensor, a gold sensor chip was used to capture the viral antigen via a self-assembled monolayer (SAM) coupling 11-mercaptoundecanoic acid and amide. The resonance angle in the direct immunoassay indicates the presence of IgM antibodies in infected sera [61].

\subsection{Detection of dengue-virus particles}

A nanoporous alumina-modified platinum electrode was proposed as an electrochemical biosensor to detect the DENV type 2 virus (DENV-2) cells [77]. This approach was based on detecting the Faradaic current response of the electrode to the redox probe, ferrocene methanol, and it is responsive to the immune-complex reaction between the targeted DENV and its monoclonal antibody inside the alumina nanochannels (Fig. 3) [77]. However, this biosensor was sensitive enough to detect DENV-2 at $1 \mathrm{pfu} \mathrm{mL}^{-1}$, but it does not have that potential with the other serotypes even when there were $10^{3} \mathrm{pfu} \mathrm{mL}^{-1}$; this nanobiosensor has potential for mosquito surveillance in the field.

In another study, a nanoporous alumina biosensor was used to investigate the response to the specific binding of dengue serotype 2 (Denv2) viral particles to its serotype 2-specific immunoglobulin $G$ antibody within a thin alumina layer by using the Faradaic electrochemical-impedance technique, and the detection sensitivity was similar to the previous study, $1 \mathrm{pfu} \mathrm{mL}^{-1}$ [78]. Although the impedimentary-based biosensor requires a long time (because it is monitoring a whole spectrum in a wide frequency region), it could still find a market because it is portable, and has low cost and acceptable sensitivity [49].

Recently, an immunocapture-based biosensor was suggested by Chen and colleagues [63] for detecting DV1 using magnetic beads that were coated with monoclonal antibody against DV1 E protein and attached to a matrix prepared by a seed-layer method as suitable for protein detection by matrix-assisted laser desorption/ ionization time-of-flight mass spectrometry (MALDI-TOF-MS). Although the DV1 LOD was 105 pfu $\mathrm{mL}^{-1}$, which is $100-1000$ fold less than the number of particles in DF and DHF patients' sera three days after onset of the disease, serotype-specific diagnosis of DENV is useful in epidemiological studies but not clinical diagnosis, when there might be more than one serotype circulating in the infected region.

\subsection{Antigen detection}

Considering AuNPs with polyvinyl butyral (PVB) [64], concanavalin A [65], polyaniline hybrid [66] or $\mathrm{Fe}_{3} \mathrm{O}_{4}$ NPs [67], all of these models were designed to detect glycoproteins and immune-response products from patients who were infected by the DENV by immobilizing lectins (proteins or glycoproteins from different sources). The majority of the serum proteins are glycosylated if there is any disease infection, and glycoproteins are changed to abnormal glycoproteins (e.g., liver disease, cancer or DF). These changes could provide the basis for clinical tests [86]. Unfortunately, the presence of these glycoproteins might be due to a DENV infection or other diseases.
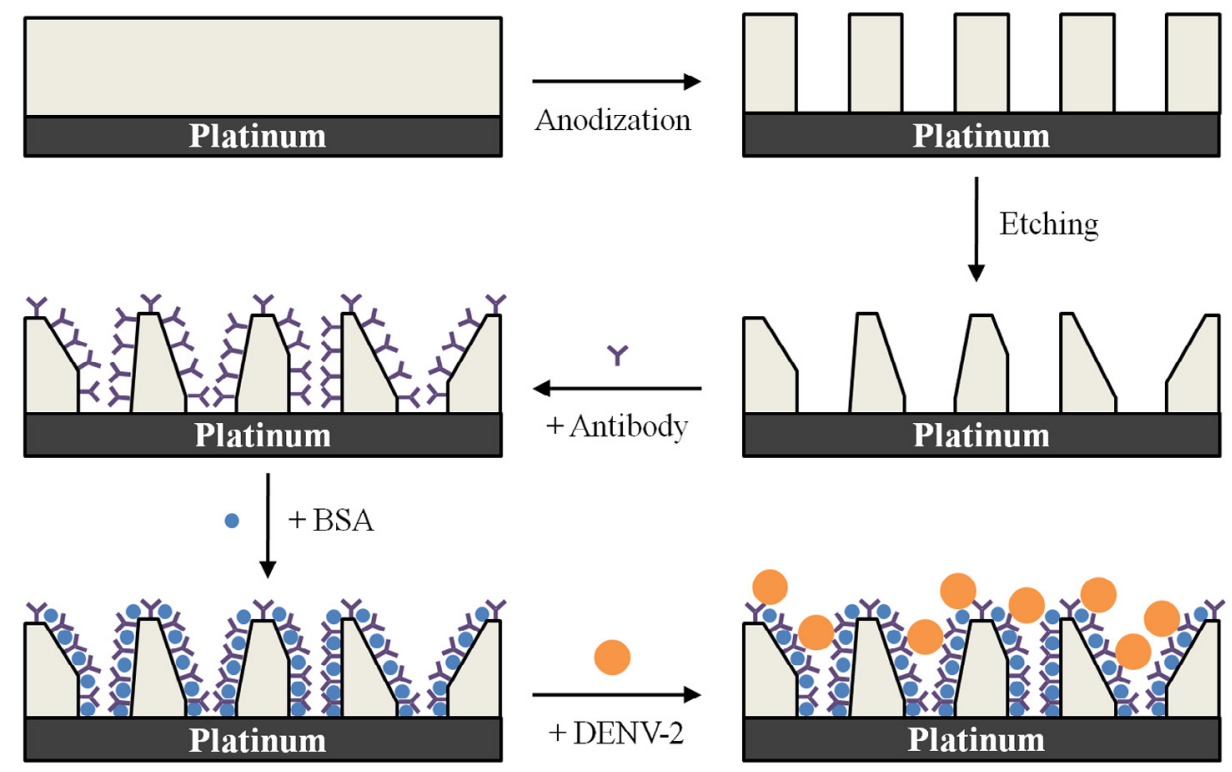

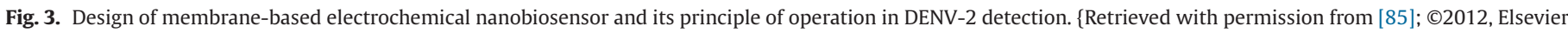
BV\}. 
The structural envelope protein (E-protein) has also been used to detect dengue infection, and a chitosan-carbon-fiber electrode (CFE) fabricated biosensor was proposed for this purpose. On the surface of the biosensor, anti-DENV antibodies were fixed on the chitosan (CHIT) matrix. The result of amperometric measurements showed sensitive detection with an LOD of $0.94 \mathrm{ng} \mathrm{mL}^{-1}$ [79]. However, E-protein is mutual among other flaviviruses, and E-protein cross reactivity can affect the sensitivity of the assay when it is used in an endemic region where other flaviviruses are circulating [87].

Piezoelectric-based sensors have been used in many research studies for dengue-antigen detection, and NS1 antigen is one of them. QCM was proposed by Su et al. [53] to detect both NS1 and E-protein via a mixture of anti-NS1 monoclonal antibodies and anti-Eprotein monoclonal antibodies that are attached to the QCMimmunochip. The QCM is placed between two spacers to allow the liquid to be in contact with one side only and, subsequently, this arrangement can help to produce oscillations (Fig. 4). The results showed that the sensitivity was higher by 100 -fold than the sandwich ELISA assay and the LOD for this method was $0.05 \mu \mathrm{g} \mathrm{mL}^{-1}$ [53]. To decrease the dilution percentage and to raise the sensitivity limit, $\mathrm{Wu}$ and his co-workers [54] used the QCM to produce an immunochip by using a couple of monoclonal antibodies ( $\mathrm{mAb} 17-2$ for E-protein) and ( $\mathrm{MAb}$ 8-1 for protein NS1) onto the QCM surface covered with protein A. However, there was no improvement in the LOD in the patient samples because the LOD was $1.727 \pm 0.291 \mu \mathrm{g}$ $\mathrm{mL}^{-1}$ and $0.740 \pm 0.191 \mu \mathrm{g} \mathrm{mL}^{-1}$ for dengue E and NS-1 protein, respectively [54].

Recently, Dias and colleagues [68] developed an immunosensor to detect NS1 (a non-structured protein) by binding anti-NS1 antibodies to carbon nanotube-screen-printed electrodes (CNT-SPEs) via an ethylene diamine film. The LOD in this study using a spiked blood-serum sample was $12 \mathrm{ng} \mathrm{mL}^{-1}$, and the sensitivity was 85.59 $\mu \mathrm{A} \mathrm{mM}^{-1} \mathrm{~cm}^{-2}$. The LOD and sensitivity would be considered satisfactory for the viral detection if the same results could be achieved using sera from real patients.

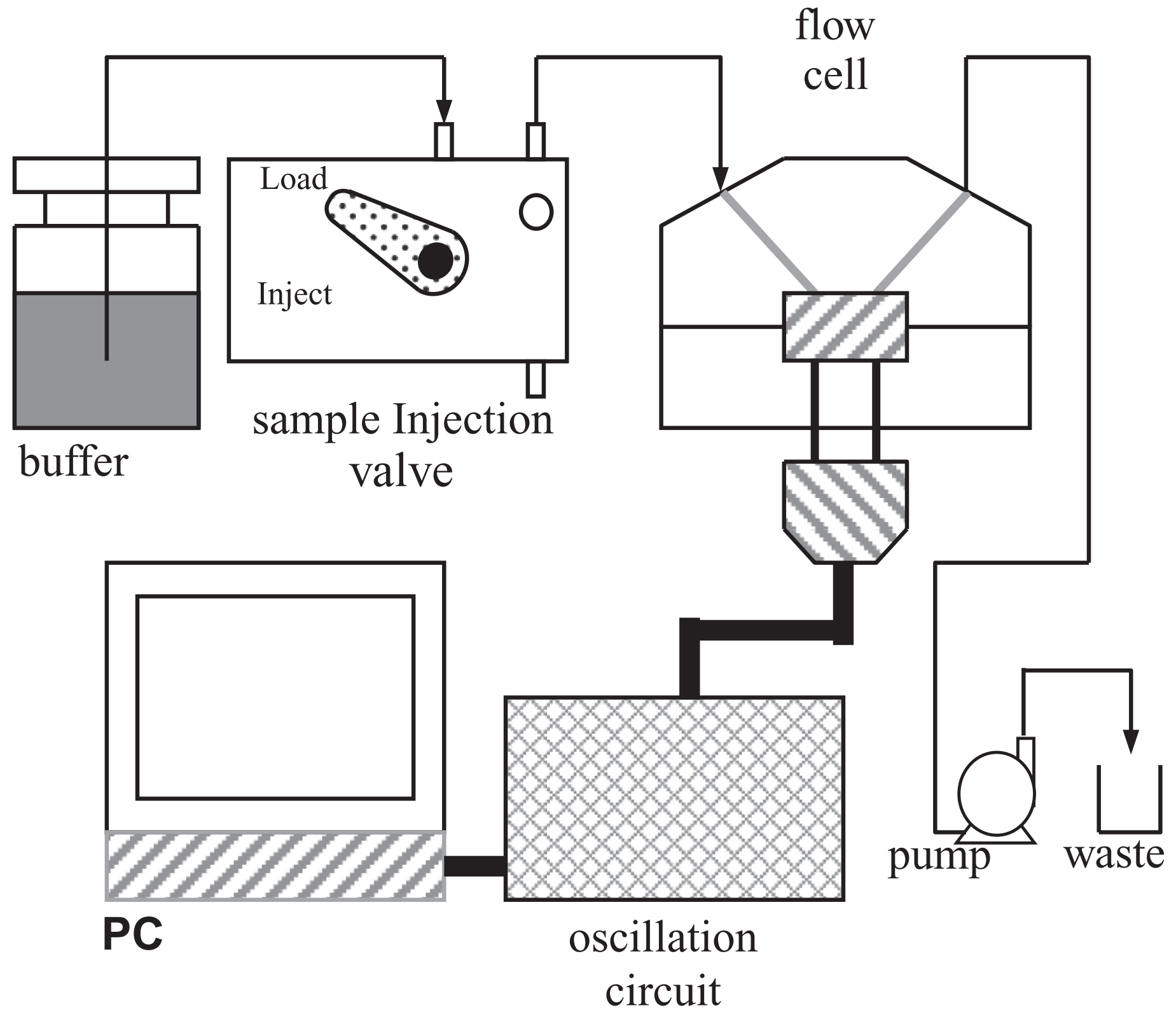

Fig. 4. Flow-injection system. \{Retrieved with permission from [73]; @2002, Elsevier BV\}. 


\section{Primary Dengue Infection}

\section{Secondary Dengue Infection}

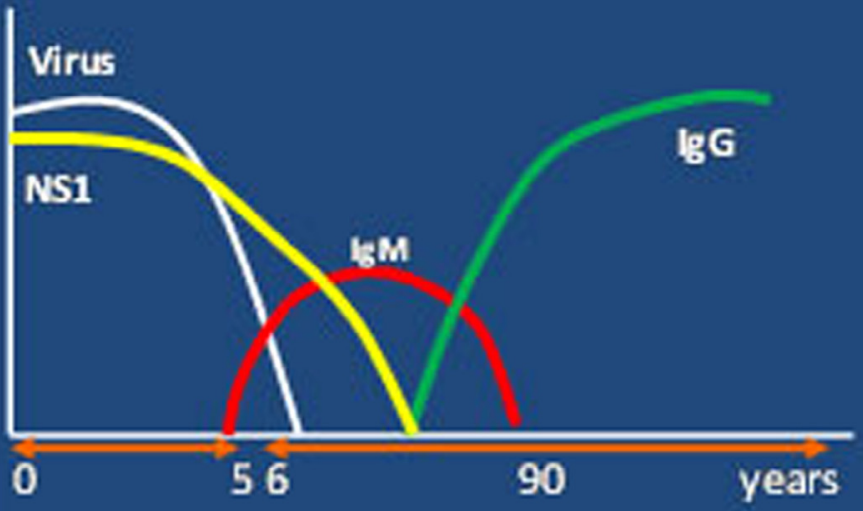

Days Post-Onset of Symptoms

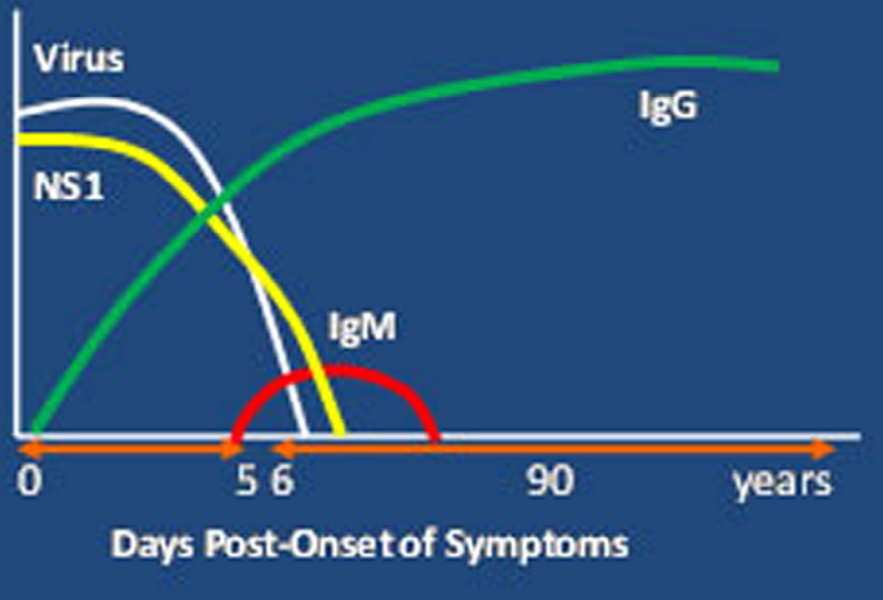

Fig. 5. Immunological response to dengue infection. \{Retrieved from [64]; Centers for Disease Control and Prevention, USA\}.

\section{Future perspectives}

Simultaneous detection of the two analytes that represent the two different stages of a dengue infection involves the following:

- the viremia phase using RNA or one of dengue antigens as the first analyte; and,

- the fever phase using IgG or IgM as the second analyte (Fig. 5) [87].

Simultaneous diagnosis is valuable because it allows better management and fast clinical follow up, especially because DF can be found with a broad range of symptoms, from basically asymptomatic to harsh disease.

The NS1 antigen can be a promising alternative for the serum glycoprotein, because it is a highly conserved antigen [88] and is specific for the DENV infection; also, it was non-reactive with sera from patients who were infected with other viral diseases, such as West Nile virus, yellow fever virus [89] or Japanese encephalitis [90]. Moreover, unlike viral nucleic acid and viral cells, NS1 presents at high concentrations in sera of dengue-infected patients from day 1 to days $9-18$ after the onset of fever [88,91]. This circumstance means that NS1 is detectable during the early clinical phase of the disease [92,93] and for a longer time [94], and NS1 protein could be detected even when the viral RNA detection was negative [88].

\section{Conclusions}

Dengue infection is known as one of the worst deadly diseases to threaten human life. Sickness with the DENV might entail no symptoms, or the symptoms might be similar to other virus diseases. Because of the absence of an efficient treatment or vaccine, a proper diagnostic technique is necessary to detect the disease consistently and rapidly.

Existing methods by isolating the virus or detecting specific dengue antibodies are exhausting and require a large amount of time.

The PCR method, even though it is fast for diagnosis in the early stage, demands high technical skills, and contamination from non-template PCR present in the laboratory environment can cause a problem.

Biosensors involve effective techniques to overcome all of these limitations. The biosensors for DENV diagnosis can be performed by targeting viral nucleic acids; however, because the dengue viral nucleic acids are kept inside the viral cell, the lysis step is necessary before the other steps in the test can be performed. Moreover, the quantity of viral nucleic acid outside the viral cell is very small and in an unstable form.

Immunosensors have potential because of their specific interaction between antigen and antibody protein and because of their capability of detecting very low concentrations of analytes from different mixtures of specimen.

\section{Acknowledgments}

This work was financially supported by a University of Malaya Research Grant (UMRG) (RG159-12SUS, RP012C-14SUS), the Fundamental Research Grant Scheme (FRGS) from the Ministry of Higher Education of Malaysia (MOHE) (FP014-2013A), a High Impact Research Grant from the Ministry of Higher Education of Malaysia (HIR-MoHE F000004-21001), and a University of Malaya Postgraduate Research Grant (PG120-2012B).

\section{References}

[1] M. Bessaud, B.A.M. Pastorino, C.N. Peyrefitte, D. Rolland, M. Grandadam, H.J Tolou, Functional characterization of the NS2B/NS3 protease complex from seven viruses belonging to different groups inside the genus Flavivirus, Virus Res. 120 (2006) 79-90.

[2] S.P. Lim, Q.-Y. Wang, C.G. Noble, Y.-L. Chen, H. Dong, B. Zou, et al., Ten years of dengue drug discovery: progress and prospects, Antiviral Res. 100 (2013) 500-519.

[3] S. Bhakat, W. Karubiu, V. Jayaprakash, M.E.S. Soliman, A perspective on targeting non-structural proteins to combat neglected tropical diseases: dengue, west nile and chikungunya viruses, Eur. J. Med. Chem. 87 (2014) 677-702.

[4] E.A. Ashley, Dengue fever, Trends Anaesth. Crit. Care 1 (2011) 39-41.

[5] K.D. Decker, Dengue fever: re-emergence of an old virus, J. Nurse Pract. 8 (2012) 389-393.

[6] I. Dale Carroll, S. Toovey, A.V. Gompel, Dengue fever and pregnancy- a review and comment, Travel Med. Infect. Dis. 5 (2007) 183-188.

[7] A.S. Bakshi, Dengue fever, DHF and DSS, Apollo Med. 4 (2007) 111-117. 
[8] M.G. Guzman, G. Kouri, Dengue and dengue hemorrhagic fever in the Americas: lessons and challenges, J. Clin. Virol. 27 (2003) 1-13.

[9] R.-F. Chen, K.D. Yang, L. Wang, J.-W. Liu, C.-C. Chiu, J.-T. Cheng, Different clinical and laboratory manifestations between dengue haemorrhagic fever and dengue fever with bleeding tendency, Trans. R. Soc. Trop. Med. Hyg. 101 (2007) 1106-1113.

[10] W.F. Wright, B.S. Pritt, Update: the diagnosis and management of dengue virus infection in North America, Diagn. Microbiol. Infect. Dis. 73 (2012) 215-220.

[11] K.-I. Yamada, T. Takasaki, M. Nawa, I. Kurane, Virus isolation as one of the diagnostic methods for dengue virus infection, J. Clin. Virol. 24 (2002) 203-209.

[12] E.A. Henchal, J.M. McCown, M.C. Seguin, Rapid identification of dengue virus isolates by using monoclonal antibodies in an indirect immunofluorescent assay, Am. J. Trop. Med. Hyg. 32 (1983) 164-169.

[13] A. Suwandono, H. Kosasih, Nurhayati, R. Kusriastuti, S. Harun, C. Maaroef, et al., Four dengue virus serotypes found circulating during an outbreak of dengue fever and dengue haemorrhagic fever in Jakarta, Indonesia, during 2004, Trans. R. Soc. Trop. Med. Hyg. 100 (2006) 855-862.

[14] R. Kumaria, A. Chakravarti, Molecular detection and serotypic characterization of dengue viruses by single-tube multiplex reverse transcriptase- polymerase chain reaction, Diagn. Microbiol. Infect. Dis. 52 (2005) 311-316.

[15] B. Raengsakulrach, A. Nisalak, N. Maneekarn, P.-T. Yenchitsomanus, C. Limsomwong, A. Jairungsri, et al., Comparison of four reverse transcriptionpolymerase chain reaction procedures for the detection of dengue virus in clinical specimens, J. Virol. Methods 105 (2002) 219-232.

[16] P.K. Dash, M. Parida, S.R. Santhosh, P. Saxena, A. Srivastava, M. Neeraja, et al., Development and evaluation of a 1-step duplex reverse transcription polymerase chain reaction for differential diagnosis of chikungunya and dengue infection, Diagn. Microbiol. Infect. Dis. 62 (2008) 52-57.

[17] V. Deubel, M. Laille, J.P. Hugnot, E. Chungue, J.L. Guesdon, M.T. Drouet, et al., Identification of dengue sequences by genomic amplification: rapid diagnosis of dengue virus serotypes in peripheral blood, J. Virol. Methods 30 (1990) 41-54.

[18] K. Morita, M. Tanaka, A. Igarashi, Rapid identification of dengue virus serotypes by using polymerase chain reactio, J. Clin. Microbiol. 29 (1991) 2107-2110.

[19] R.S. Lanciotti, C.H. Calisher, D.J. Gubler, G.J. Chang, A.V. Vorndam, Rapid detection and typing of dengue viruses from clinical samples by using reverse transcriptase-polymerase chain reaction, J. Clin. Microbiol. 30 (1992) 545-551.

[20] G.J.J. Chang, D.W. Trent, A.V. Vorndam, E. Vergne, R.M. Kinney, C.J. Mitchell, An integrated target sequence and signal amplification assay, reverse transcriptasePCR-enzyme-linked immunosorbent assay, to detect and characterize flaviviruses, J. Clin. Microbiol. 32 (1994) 477-483.

[21] C.L.K. Seah, V.T.K. Chow, Y.C. Chan, Semi-nested PCR using NS3 primers for the detection and typing of dengue viruses in clinical serum specimens, J. Clin. Virol. 4 (1995) 113-120.

[22] P.T. Yenchitsomanus, P. Sricharoen, I. Jaruthasana, S.N. Pattanakitsakul, S. Nitayaphan, J. Mongkolsapaya, et al., Rapid detection and identification of dengue viruses by polymerase chain reaction (PCR), Southeast Asian J. Trop. Med. Public Health 27 (1996) 228-236.

[23] F. Meiyu, C. Huosheng, C. Cuihua, T. Xiaodong, J. Lianhua, P. Yifei, et al., Detection of Flaviviruses by reverse transcriptase-polymerase chain reaction with the universal primer set, Microbiol. Immunol. 41 (1997) 209-213.

[24] T.M. Sudiro, H. Ishiko, A.L. Rothman, D.E. Kershaw, S. Green, D.W. Vaughn, et al., Microplate-reverse hybridization method to determine dengue virus serotype, J. Virol. Methods 73 (1998) 229-235.

[25] E. Harris, T.G. Roberts, L. Smith, J. Selle, L.D. Kramer, S. Valle, et al., Typing of dengue viruses in clinical specimens and mosquitoes by single- tube multiplex reverse transcriptase PCR, J. Clin. Microbiol. 36 (1998) 2634-2639.

[26] T. Laue, P. Emmerich, H. Schmitz, Detection of dengue virus RNA in patients after primary or secondary dengue infection by using the TaqMan automated amplification system, J. Clin. Microbiol. 37 (1999) 2543-2547.

[27] H.S.H. Houng, R. Chung-Ming Chen, D.W. Vaughn, N. Kanesa-thasan, Development of a fluorogenic RT-PCR system for quantitative identification of dengue virus serotypes 1-4 using conserved and serotype-specific noncoding sequences, J. Virol. Methods 95 (2001) 19-32.

[28] S.O. De Paula, C. de Melo Lima, M.P. Torres, M.R.G. Pereira, B.A. Lopes da Fonseca, One-step RT-PCR protocols improve the rate of dengue diagnosis compared to two-step RT-PCR approaches, J. Clin. Virol. 30 (2004) 297-301.

[29] K.D.T. Hue, T.V. Tuan, H.T.N. Thi, C.T.N. Bich, H.H.L. Anh, B.A. Wills, et al., Validation of an internally controlled one-step real-time multiplex RT-PCR assay for the detection and quantitation of dengue virus RNA in plasma, J. Virol. Methods 177 (2011) 168-173.

[30] L. Rosen, M.M. Khin, U. Tin, Recovery of virus from the liver of children with fatal dengue: reflections on the pathogenesis of the disease and its possible analogy with that of yellow fever, Res. Virol. 140 (1989) 351-360.

[31] D.A. Muller, F.D. Frentiu, A. Rojas, L.A. Moreira, S.L. O-Neill, P.R. Young, A portable approach for the surveillance of dengue virus-infected mosquitoes, J. Virol. Methods 183 (2010) 90-93.

[32] K.J.L. Liew, V.T.K. Chow, Microarray and real-time RT-PCR analyses of a novel set of differentially expressed human genes in ECV304 endothelial-like cells infected with dengue virus type 2, J. Virol. Methods 131 (2006) 47-57.

[33] M. Tahir, E. Gupta, S. Salmani, M.V. Padma, M.B. Singh, L. Dar, et al., Dengue fever with papilledema: a case of dengue-3 virus infection in central nervous system, J. Clin. Virol. 37 (2006) 65-67.

[34] Y. Mizuno, A. Kotaki, F. Harada, S. Tajima, I. Kurane, T. Takasaki, Confirmation of dengue virus infection by detection of dengue virus type 1 genome in urine and saliva but not in plasma, Trans. R. Soc. Trop. Med. Hyg. 101 (2007) 738-739.

[35] I. Prado, D. Rosario, L. Bernardo, M. Alvarez, R. Rodríguez, S. Vasquez, M.G. Guzman, PCR detection of dengue virus using dried whole blood spotted on filter paper, J. Virol. Methods 125 (2005) 75-81.

[36] M.G. Guzman, G. Kouri, Dengue diagnosis, advances and challenges, Int. J. Infect. Dis. 8 (2004) 69-80.

[37] H.-S.H. Houng, R. Chung-Ming Chen, D.W. Vaughn, N. Kanesa-thasan, Development of a fluorogenic RT-PCR system for quantitative identification of dengue virus serotypes 1-4 using conserved and serotype-specific 3- noncoding sequences, J. Virol. Methods 95 (2001) 19-32.

[38] K. Lemmer, O. Donoso Mantke, H.-G. Bae, J. Groen, C. Drosten, M. Niedrig External quality control assessment in PCR diagnostics of dengue virus infections, J. Clin. Virol. 30 (2004) 291-296

[39] T.M. Barkham, Y.K. Chung, K.F. Tang, E.E. Ooi, The performance of RT-PCR compared with a rapid serological assay for acute dengue fever in a diagnostic laboratory, Trans. R. Soc. Trop. Med. Hyg. 100 (2006) 142-148.

[40] C.C. Raggi, P. Pinzani, A. Paradiso, M. Pazzagli, C. Orlando, External qualitiy assurance program for PCR amplification of genomic DNA: an Italian experience, Clin. Chem. 49 (2003) 72-91

[41] M. Anez, C. Putonti, G.E. Fox, Y. Fofanov, R.C. Willson, Exhaustive computational identification of pathogen sequences far-distant from background genomes: identification and experimental verification of human-blind dengue PCR primers, J. Biotechnol. 133 (2008) 267-276.

[42] B. Rivetz, D. Siman-Tov, E. Ambal, A.-C. Jaramillo, A. Ben-Zvi, B. Tartakovsky, et al., New dengue antibody assay with unique differential detection of IgG and IgM antibodies, Clin. Biochem. 42 (2009) 180-184.

[43] S. Vazquez, O. Valdes, M. Pupo, I. Delgado, M. Alvarez, J.L. Pelegrino, et al., MAC-ELISA and ELISA inhibition methods for detection of antibodies after yellow fever vaccination, J. Virol. Methods 110 (2003) 179-184.

[44] A.A. Nuegoonpipat, N. Panthuyosri, S. Anantapreecha, S. Chanama, A. Sa-Ngasang, P. Sawanpanyalert, et al., Cross-reactive IgM responses in patients with dengue or Japanese encephalitis, J. Clin. Virol. 42 (2008) 75-77.

[45] M. Guzman, G.J. Meschino, A.L. Dai Pra, M. Trivi, L.I. Passoni, H. Rabal, Dynamic laser speckle: decision models with computational intelligence techniques. Proc. SPIE 7387, Speckle: Optical Metrology, 738717. 2010.

[46] C.-H. Huang, L.-L. Kuo, K.D. Yang, P.-S. Lin, P.-L. Lu, C.-C. Lin, et al., Laboratory diagnostics of dengue fever: an emphasis on the role of commercial dengue virus nonstructural protein 1 antigen rapid test, J. Microbiol. Immunol. Infect. 46 (2013) 358-365.

[47] B. Shenoy, A. Menon, S. Biradar, Diagnostic utility of dengue NS1 antigen, Pediatr Infect. Dis. 6 (2014) 110-113.

[48] W. Watthanaworawit, P. Turner, C.L. Turner, A. Tanganuchitcharnchai, R.G. Jarman, S.D. Blacksell, et al., A prospective evaluation of diagnostic methodologies for the acute diagnosis of dengue virus infection on the Thailand-Myanmar border, Trans. R. Soc. Trop. Med. Hyg. 105 (2011) 32-37.

[49] F.S. Teles, Biosensors and rapid diagnostic tests on the frontier between analytical and clinical chemistry for biomolecular diagnosis of dengue disease: a review, Anal. Chim. Acta 687 (2011) 28-42.

[50] H. Zhang, W. Li, J. Wang, H. Peng, X. Che, X. Chen, et al., NS1-based tests with diagnostic utility for confirming dengue infection: a meta-analysis, Int. J. Infect. Dis. 26 (2014) 57-66.

[51] D.R. Kryscio, N.A. Peppas, Critical review and perspective of macromolecularly imprinted polymers, Acta Biomater. 8 (2012) 461-473.

[52] S.H. Chen, Y.C. Chuang, Y.C. Lu, H.C. Lin, Y.L. Yang, C.S. Lin, A method of layer-by-layer gold nanoparticle hybridization in a quartz crystal microbalance DNA sensing system used to detect dengue virus, Nanotechnology 20 (2009) 215501.

[53] C.-C. Su, T.-Z. Wu, L.-K. Chen, H.-H. Yang, D.-F. Tai, Development of immunochips for the detection of dengue viral antigens, Anal. Chim. Acta 479 (2003) 117-123.

[54] T.-Z. Wu, C.-C. Su, L.-K. Chen, H.-H. Yang, D.-F. Tai, K.-C. Peng, Piezoelectric immunochip for the detection of dengue fever in viremia phase, Biosens. Bioelectron. 21 (2005) 689-695.

[55] D.F. Tai, C.Y. Lin, T.Z. Wu, J.H. Huang, P.Y. Shu, Artificial receptors in serologic tests for the early diagnosis of dengue virus infection, Clin. Chem. 52 (2006) 1486-1491.

[56] A.J. Baeumner, N.A. Schlesinger, N.S. Slutzki, J. Romano, E.M. Lee, R.A. Montagna, Biosensor for dengue virus detection: sensitive, rapid, and serotype specific, Anal. Chem. 74 (2002) 1442-1448.

[57] N.V. Zaytseva, R.A. Montagna, A.J. Baeumner, Microfluidic biosensor for the serotype-specific detection of dengue virus RNA, Anal. Chem. 77 (2005) 7520-7527.

[58] S.J. Fletcher, L.W. Phillips, A.S. Milligan, S.J. Rodda, Toward specific detection of dengue virus serotypes using a novel modular biosensor, Biosens. Bioelectron. 26 (2010) 1696-1700.

[59] D. Atias, Y. Liebes, V. Chalifa-Caspi, L. Bremand, L. Lobel, R.S. Marks, et al., Chemiluminescent optical fiber immunosensor for the detection of IgM antibody to dengue virus in humans, Sens. Actuators B Chem. 140 (2009) 206-215.

[60] Y.F. Lee, K.Y. Lien, H.Y. Lei, G.B. Lee, An integrated microfluidic system for rapid diagnosis of dengue virus infection, Biosens. Bioelectron. 25 (2009) 745-752.

[61] S. Kumbhat, K. Sharma, R. Gehlot, A. Solanki, V. Joshi, Surface plasmon resonance based immunosensor for serological diagnosis of dengue virus infection, J. Pharm. Biomed. Anal. 52 (2010) 255-259.

[62] J. Melendez, R. Carr, D. Bartholomew, H. Taneja, S. Yee, C. Jung, et al. Development of a surface plasmon resonance sensor for commercial applications, Sens. Actuators B Chem. 39 (1997) 375-379. 
[63] W.-H. Chen, I.H. Hsu, Y.-C. Sun, Y.-K. Wang, T.-K. Wu, Immunocapture couples with matrix-assisted laser desorption/ionization time-of-flight mass spectrometry for rapid detection of type 1 dengue virus, J. Chromatogr. A 1288 (2013) 21-27.

[64] M.D.L. Oliveira, M.T.S. Correia, F.B. Diniz, A novel approach to classify serum glycoproteins from patients infected by dengue using electrochemical impedance spectroscopy analysis, Synth. Met. 159 (2009b) 2162-2164.

[65] M.D.L. Oliveira, M.T.S. Correia, F.B. Diniz, Concanavalin A and polyvinyl butyral use as a potential dengue electrochemical biosensor, Biosens. Bioelectron. 25 (2009a) 728-732.

[66] C.A.S. Andrade, M.D.L. Oliveira, C.P. de Melo, L.C.B.B. Coelho, M.T.S. Correia, M.L. Nogueira, et al., Diagnosis of dengue infection using a modified gold electrode with hybrid organica-inorganic nanocomposite and Bauhinia monandra lectin, J. Colloid Interface Sci. 362 (2011) 517-523.

[67] M.D.L. Oliveira, M.L. Nogueira, M.T.S. Correia, L.C.B.B. Coelho, C.A.S. Andrade, Detection of dengue virus serotypes on the surface of gold electrode based on cratylia mollis lectin affinity, Sens. Actuators B Chem. 155 (2011) 789-795.

[68] A.C.M.S. Dias, S.L.R. Gomes-Filho, M.M.S. Silva, R.F. Dutra, A sensor tip based on carbon nanotube-ink printed electrode for the dengue virus NS1 protein, Biosens. Bioelectron. 44 (2013) 216-221.

[69] A. Gole, C. Dash, V. Ramakrishnan, S.R. Sainkar, A.B. Mandale, M. Rao, et al., Pepsin-gold colloid conjugates: preparation, characterization, and enzymatic activity, Langmuir 17 (2001) 1674-1679.

[70] J. Wang, L.A. Luck, I.I. Suni, Immobilization of the glucose-galactose receptor protein onto a Au electrode through a genetically engineered cysteine residue, Electrochem. Solid-State Lett. 10 (2007) J33-J36.

[71] S. Kwakye, V.N. Goral, A.J. Baeumner, Electrochemical microfluidic biosensor for nucleic acid detection with integrated minipotentiostat, Biosens. Bioelectron. 21 (2006) 2217-2223.

[72] C. Rivet, H. Lee, A. Hirsch, S. Hamilton, H. Lu, Microfluidics for medical diagnostics and biosensors, Chem. Eng. Sci. 66 (2011) 1490-1507.

[73] F.R.R. Teles, D.M.F. Dos Prazeres, J.L. De Lima-Filho, Electrochemical detection of a dengue-related oligonucleotide sequence using ferrocenium as a hybridization indicator, Sensors 7 (2007) 2510-2518.

[74] E. Martins De Souza, G.A. Nascimento, N.A. Santana, D. Bruneska, J.L. Lima Filho, Development of electrochemical biosensor for virus dengue diagnostic using graphite electrode, New Biotechnol. 25 (2009) S378.

[75] S.S. Iqbal, M.W. Mayo, J.G. Bruno, B.V. Bronk, C.A. Batt, J.P. Chambers, A review of molecular recognition technologies for detection of biological threat agents, Biosens. Bioelectron. 15 (2000) 549-578.

[76] H.P.O. Nascimento, M.D.L. Oliveira, C.P. de Melo, G.J.L. Silva, M.T. Cordeiro, C.A.S. Andrade, An impedimetric biosensor for detection of dengue serotype at picomolar concentration based on gold nanoparticles-polyaniline hybrid composites, Colloids Surf. B. Biointerfaces 86 (2011) 414-419.

[77] M.S. Cheng, J.S. Ho, C.H. Tan, J.P.S. Wong, L.C. Ng, C.-S. Toh, Development of an electrochemical membrane-based nanobiosensor for ultrasensitive detection of dengue virus, Anal. Chim. Acta 725 (2012) 74-80.

[78] B.T.T. Nguyen, A.E.K. Peh, C.Y.L. Chee, K. Fink, V.T.K. Chow, M.M.L. Ng, et al., Electrochemical impedance spectroscopy characterization of nanoporous alumina dengue virus biosensor, Bioelectrochemistry 88 (2012) 15-21.

[79] I.T. Cavalcanti, B.V.M. Silva, N.G. Peres, P. Moura, M.D.P.T. Sotomayor, M.I.F. Guedes, et al., A disposable chitosan-modified carbon fiber electrode for dengue virus envelope protein detection, Talanta 91 (2012) 41-46
[80] A.J. Baeumner, M.C. Humiston, R.A. Montagna, R.A. Durst, Detection of viable oocysts of Cryptosporidium parvum following nucleic acid sequence based amplification, Anal. Chem. 73 (2001) 1176-1180.

[81] S.J. Wu, E.M. Lee, R. Putvatana, R.N. Shurtliff, K.R. Porter, W. Suharyono, et al., Detection of dengue viral RNA using a nucleic acid sequence-based amplification assay, J. Clin. Microbiol. 39 (2001) 2794-2798.

[82] W.J.H. McBride, Evaluation of dengue NS1 test kits for the diagnosis of dengue fever, Diagn. Microbiol. Infect. Dis. 64 (2009) 31-36.

[83] A. Houde, D. Leblanc, E. Poitras, P. Ward, J. Brassard, C. Simard, et al., Comparative evaluation of RT-PCR, nucleic acid sequence-based amplification (NASBA) and real-time RT-PCR for detection of noroviruses in faecal material, J. Virol. Methods 135 (2006) 163-172.

[84] J. Mairhofer, K. Roppert, P. Ertl, Microfluidic systems for pathogen sensing: a review, Sensors 9 (2009) 4804-4823.

[85] G.-J. Zhang, L. Zhang, M.J. Huang, Z.H.H. Luo, G.K.I. Tay, E.-J.A. Lim, et al., Silicon nanowire biosensor for highly sensitive and rapid detection of dengue virus, Sens. Actuators B Chem. 146 (2010) 138-144.

[86] G.A. Turner, N-glycosylation of serum proteins in disease and its investigation using lectins, Clin. Chim. Acta 208 (1992) 149-171.

[87] CDC. Laboratory guidance and diagnostic testing. Available from: <http://www.cdc.gov/dengue/clinicalLab/laboratory.html>, 2010 (accessed 28.6.12).

[88] S. Alcon, A. Talarmin, M. Debruyne, A. Falconar, V. Deubel, M. Flamand, Enzyme-linked immunosorbent assay specific to dengue virus type 1 nonstructural protein NS1 reveals circulation of the antigen in the blood during the acute phase of disease in patients experiencing primary or secondary infections, J. Clin. Microbiol. 40 (2002) 376-381.

[89] V. Kumarasamy, A.H.A. Wahab, S.K. Chua, Z. Hassan, Y.K. Chem, M. Mohamad, et al., Evaluation of a commercial dengue NS1 antigen-capture ELISA for laboratory diagnosis of acute dengue virus infection, J. Virol. Methods 140 (2007) 75-79.

[90] M.P. Singh, M. Majumdar, G. Singh, K. Goyal, K. Preet, A. Sarwal, et al., NS1 antigen as an early diagnostic marker in dengue: report from India, Diagn. Microbiol. Infect. Dis. 68 (2010) 50-54.

[91] H. Xu, B. Di, Y.X. Pan, L.W. Qiu, Y.D. Wang, W. Hao, et al., Serotype 1-specific monoclonal antibody-based antigen capture immunoassay for detection of circulating nonstructural protein NS1: implications for early diagnosis and serotyping of dengue virus infections, J. Clin. Microbiol. 44 (2006) 28722878.

[92] D.H. Libraty, P.R. Young, D. Pickering, T.P. Endy, S. Kalayanarooj, S. Green, et al., High circulating levels of the dengue virus nonstructural protein NS1 early in dengue illness correlate with the development of dengue hemorrhagic fever, J. Infect. Dis. 186 (2002) 1165-1168.

[93] P.R. Young, P.A. Hilditch, C. Bletchly, W. Halloran, An antigen capture enzymelinked immunosorbent assay reveals high levels of the dengue virus protein NS1 in the sera of infected patients, J. Clin. Microbiol. 38 (2000) 1053-1057.

[94] E. Huhtamo, E. Hasu, N.Y. Uzcátegui, E. Erra, S. Nikkari, A. Kantele, et al., Early diagnosis of dengue in travelers: comparison of a novel real-time RT-PCR, NS1 antigen detection and serology, J. Clin. Virol. 47 (2010) 49-53. 